\title{
Sociodemographic differences in single, dual, and poly tobacco use among Appalachian youth
}

\author{
Delvon T. Mattingly', Joy L. Hart' ${ }^{1,2,3}$, Lindsey A. Wood ${ }^{1,3}$, Kandi L. Walker ${ }^{1,2,3}$
}

\begin{abstract}
INTRODUCTION Patterns of youth tobacco use, including use of multiple products, have likely shifted as e-cigarettes have grown in popularity. However, there is limited understanding of dual and poly tobacco use and the associated disparities, especially among Appalachian youth.

METHODS We analyzed Youth Appalachian Tobacco Study data $(n=1116)$ to estimate prevalence of current (past-30 day) cigarette, e-cigarette, and smokeless tobacco use by gender, race/ethnicity, age, school type, state, smartphone use, and number of household tobacco users. We created a pattern of tobacco use variable (i.e. never, former, single, dual, poly) based on all possible combinations of the included products. Using multivariable multinomial logistic regression (outcome reference: never use), we evaluated associations between sociodemographic characteristics and patterns of tobacco use.

RESULTS Former (16.2\%) was the most common tobacco use group, followed by single $(10.8 \%)$, dual (4.5\%), and poly $(2.4 \%)$ use. Dual and poly use were more prevalent among males, Whites/Caucasians, older participants, and participants living in households with tobacco users. Kentucky residents (vs New York) had higher odds of dual use ( $\mathrm{OR}=5.15 ; 95 \%$ CI: $1.72-15.44)$, and youth who used smartphones for $\geq 20$ hours/week (vs $<20$ hours/week) had greater odds of poly use $(\mathrm{OR}=3.02$; $95 \%$ CI: $1.34-6.80)$.

CONCLUSIONS Differences in single, dual, and poly tobacco use were evidenced by sociodemographic characteristics. Additional inquiry should further examine these disparities so that tobacco prevention interventions can be appropriately tailored.
\end{abstract}

\section{AFFILIATION \\ 1 Department of Communication, University of Louisville, Louisville, United States \\ 2 American Heart Association Tobacco Center for Regulatory Science, Dallas, United States 3 School of Medicine, Envirome Institute, University of Louisville, Louisville, United States}

\section{CORRESPONDENCE TO}

Joy L. Hart. University of Louisville, Department of Communication, Louisville, KY 40292, United States. E-mail: joy.hart@louisville.edu ORCID ID: https://orcid.org/00000003-3220-2638

\section{KEYWORDS}

tobacco, youth, electronic cigarettes, Appalachia, poly tobacco use, dual tobacco use

Received: 29 April 2020

Revised: 10 June 2020

Accepted: 29 June 2020

\section{INTRODUCTION}

Although the marketplace of tobacco products has changed across time, consumption of tobacco continues to be the chief cause of preventable death in the US ${ }^{1,2}$. Patterns of youth tobacco use have evolved ${ }^{3}$, but exposure to tobacco continues to put youths at heightened risk for experimentation and continued use $^{4}$. Despite this fact, the tobacco industry persists in promoting emerging products to encourage youth uptake $^{5}$. As a result, concurrent use of two or more tobacco products is of growing public health interest. However, few studies have examined youths' poly tobacco use $\mathrm{e}^{6,7}$, especially among vulnerable groups such as Appalachian youths.

Among youths, e-cigarettes have become the most commonly used tobacco product ${ }^{3}$, with the most popular combination of products being e-cigarettes and cigarettes ${ }^{7}$. However, some evidence points to heterogeneity in dual and poly tobacco use by sociodemographic characteristics. For example, dual and poly tobacco use is more prevalent among high schoolers $(29.9 \%)$ than middle schoolers $(11.5 \%)^{3}$. Poly tobacco use has been found to be positively associated with being male and non-Hispanic White 
relative to single-product use ${ }^{6}$, and dual and poly tobacco use are more prevalent in rural areas than urban areas in the $\mathrm{US}^{8}$. Additionally, poly tobacco use, relative to single-product use, is associated with greater risk for nicotine dependence and other deleterious health outcomes ${ }^{9,10}$, warranting investigation of these use patterns among at-risk youth.

Appalachian youths are susceptible to tobacco consumption for several reasons. Factors contributing to Appalachian youth tobacco exposure and use include cultural values that often accept and perpetuate tobacco use and area histories of raising and working with tobacco crops $^{11}$. Furthermore, the Appalachian region ranks higher in tobacco use and poverty than the national average ${ }^{12,13}$. With high tobacco use in the region, Appalachian youth often have family members, teachers, and other trusted adults and role models who use tobacco ${ }^{14}$. In addition, tobacco companies have long targeted rural areas with product marketing and advertising ${ }^{15}$. Further, rural youth are less often exposed to anti-tobacco campaigns than youth in urban areas ${ }^{15}$. Sustained tobacco product advertising, community acceptance of tobacco use, and youth exposure to tobacco products and use, combined with less awareness of anti-tobacco messaging, contribute to youth tobacco use rates in the region, which exceed the national average ${ }^{11}$. Thus, given these contributing factors and overall use rates, Appalachian youths may be vulnerable to dual and poly tobacco use. This study examines prevalence and sociodemographic correlates of single, dual, and poly tobacco use in a sample of Appalachian youths. We aim to determine, specifically, dual and poly use patterns among sociodemographic groups.

\section{METHODS}

\section{Study design}

We analyzed data from the Youth Appalachian Tobacco Study (YATS) $(n=1116)$. This crosssectional study was approved by the (University of Louisville) Institutional Review Board and conducted between 2014 and 2016 to examine tobacco use patterns, sources of tobacco exposure, and perceptions and attitudes surrounding tobacco products among Appalachian youth. Middle and high school students in three Appalachian states, Kentucky, North Carolina, and New York, were invited to participate. Tobacco use rates guided the selection of the three states. Youth tobacco use was high in Kentucky, moderate in North Carolina, and low in New York $(17.9 \%, 15.0 \%$, and $10.6 \%$, respectively ${ }^{16}$. Students in schools in three Kentucky counties, three North Carolina counties, and two New York counties participated.

Parents or guardians received a letter prior to data collection and could decline their child's participation; students were given assent forms on the day of data collection in their school and could decline participation. Questionnaires were completed during regular school hours in approximately 40 minutes. YATS is described in more detail elsewhere ${ }^{17}$.

\section{Measures}

\section{Sociodemographic characteristics}

We used the following sociodemographic characteristics: gender (male vs female), race/ ethnicity, age, school type (middle vs high), state (New York vs Kentucky vs North Carolina), smartphone use ( $<20$ vs $\geq 20$ hours/week), and number of household tobacco users (zero vs $\geq 1$ ). Race/ethnicity included the following categories: African American, Hispanic, White, Asian, and Other. This variable was dichotomized into White/Caucasian and non-White/ non-Caucasian. The number of household tobacco users measure excluded the participant.

\section{Tobacco use}

Tobacco products examined were cigarettes, e-cigarettes, and smokeless tobacco. We defined current use as past-month use for each product. We created a pattern of tobacco use variable (i.e. never, former, single, dual, poly) based on exclusive use of each of the included products (single), any combination of two products (dual), and use of all three products (poly). Never users were participants who had never used tobacco. Former users were youth who indicated past, but not current, use of one or more of the included products.

\section{Statistical analysis}

We computed prevalence estimates for patterns of tobacco use overall and by sociodemographic characteristics. Using analysis of variance and $\chi^{2}$ 
tests, we examined characteristics across tobacco use categories. We estimated adjusted odds ratios and $95 \%$ confidence intervals for associations between sociodemographic characteristics and patterns of tobacco use (reference: never use) using multivariable multinomial logistic regression. School type was included in the model in place of age to avoid multicollinearity. We analyzed data using SAS 9.4 (Cary, NG).

\section{RESULTS}

Table 1 displays participant sociodemographic characteristics stratified by tobacco use. The gender distribution was nearly even (51.1\% male, $48.9 \%$ female). The sample was predominantly White/ Caucasian $(88.6 \%)$. The mean age was 13.7 years
$(\mathrm{SD}=1.9)$ with a median of 14 years (range: $11-$ 19). The majority of respondents were from North Carolina (46.4\%), followed by Kentucky (34.1\%) and then New York (19.5\%). About one-third (32.8\%) used smartphones for $\geq 20$ hours/week, and slightly more than half (57.3\%) had households with tobacco users. Nearly a tenth of the sample were single users (10.8\%), $4.5 \%$ were dual users, and $2.4 \%$ were poly users. The most popular dual use groups were cigarettes and smokeless tobacco $(2.1 \%)$ and cigarettes and e-cigarettes (1.9\%) (Supplementary file, Table S1).

Frequencies of dual and poly use were higher in males, Whites/Caucasians, older participants, and participants living with tobacco users (Table 1). However, compared to dual use, prevalence of poly

Table 1. Participant sociodemographic characteristics by patterns of tobacco use, The Youth Appalachian Tobacco Study $(\mathrm{N}=1116)$

\begin{tabular}{|c|c|c|c|c|c|c|c|}
\hline \multirow[t]{2}{*}{ Sociodemographic characteristics } & \multicolumn{6}{|c|}{ Patterns of tobacco use, $n(\%)$} & \multirow[t]{2}{*}{$p$} \\
\hline & $\begin{array}{c}\text { Total } \\
1116(100.0)\end{array}$ & $\begin{array}{c}\text { Never } \\
738(66.1)\end{array}$ & $\begin{array}{c}\text { Former } \\
181(16.2)\end{array}$ & $\begin{array}{c}\text { Single } \\
120(10.8)\end{array}$ & $\begin{array}{c}\text { Dual } \\
50(4.5)\end{array}$ & $\begin{array}{c}\text { Poly } \\
27(2.4)\end{array}$ & \\
\hline Gender & & & & & & & $0.036^{\mathrm{a}}$ \\
\hline Male & $570(51.1)$ & $362(49.1)$ & $89(49.2)$ & $74(61.7)$ & $28(56.0)$ & $17(63.0)$ & $0.756^{b}$ \\
\hline Female & $546(48.9)$ & $376(50.9)$ & $92(50.8)$ & $46(38.3)$ & $22(44.0)$ & $10(37.0)$ & $0.977^{c}$ \\
\hline Race/ethnicity & & & & & & & $0.046^{\mathrm{a}}$ \\
\hline White/Caucasian & $989(88.6)$ & $646(87.5)$ & 159 (87.9) & 115 (95.8) & $46(92.0)$ & $23(85.2)$ & $0.118^{b}$ \\
\hline Non-White/Non-Caucasian & $127(11.4)$ & $92(12.5)$ & $22(12.1)$ & $5(4.2)$ & $4(8.0)$ & $4(14.8)$ & $0.909^{c}$ \\
\hline Age (years) & & & & & & & $<0.001^{\text {a }}$ \\
\hline Mean \pm SD & $13.7 \pm 1.9$ & $13.3 \pm 1.7$ & $14.4 \pm 1.9$ & $14.7 \pm 1.9$ & $15.1 \pm 1.8$ & $14.3 \pm 1.9$ & $0.248^{b}$ \\
\hline Median (min-max) & $14(11-19)$ & $13(11-19)$ & $14(11-19)$ & $15(11-19)$ & $15(12-18)$ & $14(11-18)$ & $<0.001^{\mathrm{c}}$ \\
\hline School type & & & & & & & $<0.001^{\mathrm{a}}$ \\
\hline Middle school & $679(60.8)$ & $508(68.8)$ & $86(47.5)$ & $55(45.8)$ & $17(34.0)$ & $13(48.2)$ & $0.311^{b}$ \\
\hline High school & $437(39.2)$ & $230(31.2)$ & $95(52.5)$ & $65(54.2)$ & $33(66.0)$ & $14(51.8)$ & $<0.001^{\mathrm{c}}$ \\
\hline State & & & & & & & $<0.001^{\mathrm{a}}$ \\
\hline New York & $218(19.5)$ & $208(28.2)$ & $72(39.8)$ & $61(50.9)$ & $27(54.0)$ & $12(44.4)$ & $0.831^{\mathrm{b}}$ \\
\hline Kentucky & $380(34.1)$ & $367(49.7)$ & $78(43.1)$ & $43(35.8)$ & $19(38.0)$ & $11(40.7)$ & $0.009^{c}$ \\
\hline North Carolina & $518(46.4)$ & $163(22.1)$ & $31(17.1)$ & $16(13.3)$ & $4(8.0)$ & $4(14.8)$ & \\
\hline Smartphone use (hours/week) & & & & & & & $<0.001^{\mathrm{a}}$ \\
\hline$<20$ & $750(67.2)$ & $520(70.5)$ & $119(65.8)$ & $72(60.0)$ & $27(54.0)$ & $12(44.4)$ & $0.314^{b}$ \\
\hline$\geq 20$ & 366 (32.8) & $218(29.5)$ & $62(34.2)$ & $48(40.0)$ & $23(46.0)$ & $15(55.6)$ & $0.217^{c}$ \\
\hline Household tobacco users ${ }^{d}$ & & & & & & & $<0.001^{\mathrm{a}}$ \\
\hline Zero & $477(42.7)$ & $364(49.3)$ & 65 (35.9) & $32(26.7)$ & $9(18.0)$ & 7 (25.9) & $0.477^{b}$ \\
\hline$\geq 1$ & $639(57.3)$ & $374(50.7)$ & $116(64.1)$ & 88 (73.3) & $41(82.0)$ & $20(74.1)$ & $0.001^{c}$ \\
\hline
\end{tabular}

a Chi-squared/Fisher's exact test (categorical) or ANOVA (continuous) p-value comparing never users, single users, dual users, and poly users. b Chi-squared/Fisher's exact test (categorical) or ANOVA (continuous) p-value comparing single users, dual users, and poly users. c Chi-squared/Fisher's exact test (categorical) or Student's t-test (continuous) $p$-value comparing never users and former users. $d$ Number of household users does not include the participant. 
Table 2. Multivariable multinomial logistic regression models of associations between participant sociodemographic characteristics and patterns of tobacco use ( $\mathrm{N}=1116)$

\begin{tabular}{|c|c|c|c|c|c|c|c|c|}
\hline \multirow[t]{3}{*}{ Sociodemographic characteristics } & \multicolumn{8}{|c|}{ Patterns of tobacco use ${ }^{a}$} \\
\hline & \multicolumn{2}{|c|}{ Former } & \multicolumn{2}{|r|}{ Single } & \multicolumn{2}{|r|}{ Dual } & \multicolumn{2}{|r|}{ Poly } \\
\hline & $\mathrm{AOR}^{b}$ & $95 \%$ CI & $A O R^{b}$ & $95 \%$ CI & $\mathrm{AOR}^{b}$ & $95 \%$ CI & $\mathrm{AOR}^{b}$ & $95 \%$ CI \\
\hline \multicolumn{9}{|l|}{ Gender } \\
\hline Male & Ref. & & Ref. & & Ref. & & Ref. & \\
\hline Female & 1.07 & $(0.76-1.51)$ & 0.59 & $(0.39-0.89)$ & 0.76 & $(0.41-1.41)$ & 0.49 & $(0.22-1.13)$ \\
\hline \multicolumn{9}{|l|}{ Race/ethnicity } \\
\hline White/Caucasian & Ref. & & Ref. & & Ref. & & Ref. & \\
\hline Non-White/Non-Caucasian & 1.33 & $(0.79-2.26)$ & 0.44 & $(0.17-1.14)$ & 0.99 & $(0.33-2.98)$ & 1.53 & $(0.49-4.81)$ \\
\hline \multicolumn{9}{|l|}{ School type } \\
\hline Middle school & Ref. & & Ref. & & Ref. & & Ref. & \\
\hline High school & 2.68 & $(1.90-3.78)$ & 2.68 & $(1.77-4.05)$ & 4.69 & $(2.50-8.81)$ & 2.25 & $(1.02-4.98)$ \\
\hline \multicolumn{9}{|l|}{ State } \\
\hline New York & Ref. & & Ref. & & Ref. & & Ref. & \\
\hline Kentucky & 1.95 & $(1.19-3.18)$ & 2.86 & $(1.55-5.27)$ & 5.15 & $(1.72-15.44)$ & 2.19 & $(0.67-7.14)$ \\
\hline North Carolina & 1.13 & $(0.71-1.80)$ & 1.28 & $(0.69-2.38)$ & 2.18 & $(0.72-6.64)$ & 1.22 & $(0.37-3.97)$ \\
\hline \multicolumn{9}{|l|}{ Smartphone use (hours/week) } \\
\hline$<20$ & Ref. & & Ref. & & Ref. & & Ref. & \\
\hline$\geq 20$ & 1.07 & $(0.74-1.54)$ & 1.58 & $(1.03-2.43)$ & 1.75 & $(0.94-3.26)$ & 3.02 & $(1.34-6.80)$ \\
\hline \multicolumn{9}{|l|}{ Household tobacco users ${ }^{c}$} \\
\hline Zero & Ref. & & Ref. & & Ref. & & Ref. & \\
\hline$\geq 1$ & 1.67 & $(1.18-2.37)$ & 2.31 & $(1.48-3.61)$ & 3.86 & $(1.82-8.21)$ & 2.68 & $(1.09-6.57)$ \\
\hline
\end{tabular}

a Ref.: the outcome reference group is 'never use'. b Adjusted odds ratios (AOR) and 95\% confidence intervals adjusted for all participant characteristics; age not included due to multicollinearity with school type. c Number does not include the participant.

use was higher in youth who used smartphones $\geq 20$ hours/week and lower in New York residents. Further, the distribution of poly use was nearly even by school type ( $48.2 \%$ middle school). Distributions among never users and any current users varied by all included sociodemographic groups $(\mathrm{p}<0.05$ for all). Conversely, single, dual, and poly use groups did not differ by covariates when examined without never users. Variation between never and former users occurred by factors such as state and number of household tobacco users ( $\mathrm{p}<0.05$ for each).

Table 2 shows associations between sociodemographic characteristics and patterns of tobacco use (reference: never use). Associations were found in all characteristics except race/ ethnicity for single use. Specifically, females (vs males) had fewer odds of single use $(\mathrm{OR}=0.59$; 95\% CI: 0.39-0.89). Dual use was more strongly associated with school type, state, and household tobacco users than was former, single, or poly use. For example, youth living in households with at least one tobacco user (vs no tobacco users) had greater odds of former, single, dual, and poly use, and the strength of association was greater for dual use ( $\mathrm{OR}=3.86$; 95\% CI: 1.82-8.21). Further, Kentucky residents (vs New York) had greater odds of former, single, and dual use, but not poly use. Youths who used smartphones $\geq 20$ hours/week (vs $<20$ hours/ week) had greater odds of single and poly use, but not former or dual use.

\section{DISCUSSION}

Our study characterizes patterns of tobacco use in a sample of Appalachian youths. Consistent with prior research, dual and poly use were more prevalent among males, Whites/Caucasians, and 
older participants ${ }^{3,6,7}$. We found that dual and poly use differed by state and smartphone use. Specifically, state was associated with former, single, and dual use, and smartphone use was associated with single and poly use. When found to be significantly associated with a sociodemographic factor, dual use had a stronger association than any other use category.

Moreover, living with one or more tobacco user(s) is associated with youth using any tobacco, including use of multiple tobacco products. Previous work with Appalachian youth found significant associations between residing in a household with one or more tobacco users and intention to try a tobacco product $^{18}$. Other research has documented positive associations between living with a tobacco user and youth use of tobacco products ${ }^{19-22}$. For example, two recent studies with Appalachian middle school students found, for those who lived in a tobacco-use household, nearly threefold increased odds for dual use $^{23}$ and an increased likelihood of trying alternative tobacco products (e.g. e-cigarettes, cigarillos) ${ }^{24}$. Tobacco use by a household member is believed to convey acceptability of product use ${ }^{25}$, and, especially in Appalachia where overall use rates are high, further normalizes tobacco's acceptability for youth.

Patterns of youth tobacco use may evolve in conjunction with shifts in the tobacco industry. These changes may lead to increases in dual and poly use with unknown health consequences. For example, e-cigarette use has been found to be associated with subsequent cigarette use in youth ${ }^{4}$. Youth e-cigarette and cigarette dual users are at higher risk for nicotine dependence ${ }^{9}$, including higher likelihood of becoming established users as they transition into adulthood ${ }^{26}$. A recent study in Tennessee, located in the Central Appalachian region, found that more than half of high school students who used e-cigarettes also used at least one other tobacco product ${ }^{27}$. Another inquiry with Tennessee Appalachian middle school students reported increases over time in dual use ${ }^{23}$. Taken together, these studies point to increasing public health concerns surrounding Appalachian youth dual and poly tobacco use.

Sociodemographic differences in dual and poly use may drive tobacco-related health disparities. Future research should seek to deepen understanding of sociodemographic factors associated with these tobacco use patterns, especially given possible increases in dual and poly use in vulnerable populations, such as Appalachian youth. For example, although we found that dual use, when significantly related to sociodemographic characteristics, had a stronger association than other tobacco use categories, additional work is needed with larger samples to more fully explicate such relationships and to examine them across time. Further work characterizing use patterns will inform tobacco interventions aimed at preventing and reducing youth tobacco consumption, and such work is especially important with vulnerable populations of youths who are more often targeted by tobacco marketing and more likely to use tobacco products.

\section{Limitations}

As with all investigations, our study has limitations. First, participants were assessed on use of cigarettes, e-cigarettes, and smokeless tobacco. However, cigars and hookah are also popular among youths ${ }^{3}$, and these products are commonly used in certain sociodemographic groups (e.g. African American youth, males). Second, due to the sample size, we could not stratify by specific combinations of use (e.g. cigarette + e-cigarette, smokeless + e-cigarette) and the precision of some estimates was hindered. Future research examining use combinations and incorporating additional products that may be popular with youths would be useful in further investigating these associations. Despite these limitations, our study is among the first to characterize patterns of dual and poly use in Appalachian youth.

\section{CONCLUSIONS}

Patterns of tobacco use vary by key sociodemographic characteristics. Specifically, dual and poly use were more prevalent among males, Whites/Caucasians, older participants, and youth living with tobacco users. High schoolers and participants living with one or more tobacco user(s) had greater odds of any tobacco use, including the use of multiple products. Our findings serve as the building blocks for future research that examines sociodemographic disparities in, and downstream health consequences of, dual and poly use among Appalachian youth. As health professionals design prevention messaging, recognizing and addressing concurrent tobacco use is vital. 


\section{REFERENCES}

1. Bhatnagar A, Whitsel LP, Blaha MJ, et al. New and emerging tobacco products and the nicotine endgame: The role of robust regulation and comprehensive tobacco control and prevention: A presidential advisory from the American Heart Association. Circulation. 2019;139(19):e937-e958. doi:10.1161/CIR.0000000000000669

2. U.S. Department of Health and Human Services. The Health Consequences of Smoking: 50 Years of Progress. A Report of the Surgeon General. Atlanta (GA): U.S. Department of Health and Human Services, Centers for Disease Control and Prevention, National Center for Chronic Disease Prevention and Health Promotion, Office on Smoking and Health; 2014. https://www.ncbi.nlm.nih. gov/books/NBK179276/pdf/Bookshelf_NBK179276. pdf. Accessed June 10, 2020.

3. Wang TW, Gentzke AS, Creamer MR, et al. Tobacco product use and associated factors among middle and high school students-United States, 2019. MMWR Surveill Summ. 2019;68(12):1-22. doi:10.15585/mmwr.ss6812a1

4. Primack BA, Soneji S, Stoolmiller M, Fine MJ, Sargent JD. Progression to traditional cigarette smoking after electronic cigarette use among US adolescents and young adults. JAMA Pediatr. 2015;169(11):1018-1023. doi:10.1001/jamapediatrics.2015.1742

5. Andrade MD, Hastings G, Angus K. Promotion of electronic cigarettes: Tobacco marketing reinvented? BMJ. 2013;347:f7473. doi:10.1136/bmj.f7473

6. Osibogun O, Taleb ZB, Bahelah R, Salloum RG, Maziak W. Correlates of poly-tobacco use among youth and young adults: Findings from the Population Assessment of Tobacco and Health study, 2013-2014. Drug Alcohol Depend. 2018;187:160-164. doi:10.1016/j.drugalcdep.2018.02.024

7. King JL, Reboussin D, Cornacchione Ross J, Wiseman KD, Wagoner KG, Sutfin EL. Polytobacco use among a nationally representative sample of adolescent and young adult e-cigarette users. J Adolesc Health. 2018;63(4):407412. doi:10.1016/j.jadohealth.2018.04.010

8. Roberts ME, Doogan NJ, Stanton CA, Quisenberry AJ, Villanti AC, Gaalema DE, et al. Rural versus urban use of traditional and emerging tobacco products in the United States, 2013-2014. Am J Public Health. 2017;107(10):15541559. doi:10.2105/AJPH.2017.303967

9. Sung HY, Wang Y, Yao T, Lightwood J, Max W. Polytobacco use and nicotine dependence symptoms among US adults, 2012-2014. Nicotine Tob Res. 2018;20(suppl_1):S88-S98. doi:10.1093/ntr/nty050

10. Stanton CA, Halenar MJ. Patterns and correlates of multiple tobacco product use in the United States. Nicotine Tob Res. 2018;20(suppl_1):S1-S4. doi:10.1093/ntr/nty081

11. Hart JL, Walker KL, Sears CG, Tompkins LK, Lee AS, Mattingly DT, et al. The 'state' of tobacco: Perceptions of tobacco among Appalachian youth in Kentucky. Tob Prev Cessat. 2018;4(January). doi:10.18332/tpc/81857

12. Centers for Disease Control and Prevention. State Tobacco
Activities Tracking and Evaluation (STATE) System. https://www.cdc.gov/statesystem/cigaretteuseyouth. html. Accessed April 19, 2020.

13. Appalachian Regional Commission. Income and poverty in Appalachia. In: The Appalachian Region: A data overview from the 2013-2017 American Community Survey. https://www.arc.gov/noindex/ research/ACS-infographics2013-2017/DataSnapshotIncomeAndPovertyInAppalachia.pdf. Accessed April 19, 2020.

14. PDA Inc., The Cecil G. Sheps Center for Health Services Research, Appalachian Regional Commission. Creating a culture of health in Appalachia: Disparities and bright spots. 2017. https://www.arc.gov/assets/research_ reports/Health_Disparities_in_Appalachia_August_2017. pdf. Accessed June 10, 2020.

15. American Lung Association. Cutting tobacco's rural roots: Tobacco use in rural communities. http://www. lcmh.com/documents/cutting-tobaccos-rural-roots.pdf. Accessed June 10, 2020.

16. Centers for Disease Control and Prevention. Behavioral Risk Factor Surveillance System, 2014. In: State Tobacco Activities Tracking and Evaluation (STATE) System. https://www.cdc.gov/statesystem/index.html. Accessed June 10, 2020.

17. Mattingly DT, Pfeiffer J, Tompkins LK, et al. Associations between Appalachian youth tobacco consumption and communication channel use. Tob Prev Cessat. 2020;6(March). doi:10.18332/tpc/118234

18. Owusu D, Mamudu HM, Robertson C, Wang L, Guy H, Collins C, Boghozian R, Littleton MA. Intention to try tobacco among middle school students in a predominantly rural environment of Central Appalachia. Subst Use Misuse. 2019;54(3):449-458. doi:10.1080/10826084.2018.1504080

19. Gilman SE, Rende R, Boergers J, Abrams DB, Buka SL, Clark MA, et al. Parental smoking and adolescent smoking initiation: An intergenerational perspective on tobacco control. Pediatrics. 2009;123(2):e274-e281. doi:10.1542/peds.2008-2251

20. O'Loughlin J, Karp I, Koulis T, Paradis G, DiFranza J. Determinants of first puff and daily cigarette smoking in adolescents. Am J Epidemiol. 2009;170(5):585-597. doi:10.1093/aje/kwp179

21. Kandel DB, Griesler PC, Hu M-C. Intergenerational patterns of smoking and nicotine dependence among US adolescents. Am J Public Health. 2015;105(11):e63-e72. doi:10.2105/AJPH.2015.302775

22. Vassoler FM, Byrnes EM, Pierce RC. The impact of exposure to addictive drugs on future generations: Physiological and behavioral effects. Neuropharmacology. 2014;76:269275. doi:10.1016/j.neuropharm.2013.06.016

23. Mamudu HM, Wang L, Owusu D, Robertson C, Collins C, Littleton MA. Prospective study of dual use of e-cigarettes and other tobacco products among school-going youth in rural Appalachian Tennessee. Ann Thorac Med. 
2019;14(2):127-133. doi:10.4103/atm.ATM_217_18

24. Owusu D, Mamudu HM, Collins C, et al. The usage and associated factors of alternative tobacco products among school-going youth in Central Appalachia. J Health Care Poor Underserved. 2019;30(1):249-264. doi:10.1353/hpu.2019.0019

25. Krishnan-Sarin S, Morean ME, Camenga DR, Cavallo DA, Kong G. E-cigarette use among high school and middle school adolescents in Connecticut. Nicotine Tob Res. 2015;17(7):810-818. doi:10.1093/ntr/ntu243

26. Chaffee BW, Watkins SL, Glantz SA. Electronic cigarette use and progression from experimentation to established smoking. Pediatrics. 2018;141(4):e20173594. doi:10.1542/peds.2017-3594

27. Owusu D, Aibangbee J, Collins C, et al. The use of e-cigarettes among school-going adolescents in a predominantly rural environment of Central Appalachia. J Community Health. 2017;42(3):624-631. doi:10.1007/s10900-016-0297-0

\section{ACKNOWLEDGEMENTS}

We thank Clara Sears, Alex Lee, Courteney Smith, and Allison Siu for assisting with data collection and Shesh Rai for assisting with the analyses. We also acknowledge the University of Louisville's research computing group and the Cardinal Research Cluster, whose resources facilitated our work.

\section{CONFLICTS OF INTEREST}

The authors have each completed and submitted an ICMJE form for disclosure of potential conflicts of interest. The authors declare that they have no competing interests, financial or otherwise, related to the current work. J. L. Hart and K. Walker report grants from the National Institutes of Health during the conduct of the study.

\section{FUNDING}

This work was supported, in part, by the National Heart, Lung, and Blood Institute (NHLBI) of the National Institutes of Health (NIH) and FDA Center for Tobacco Products under Award Numbers P50HL120163 and U54HL120163. The content is solely the responsibility of the authors and does not necessarily represent the official views of the the $\mathrm{NIH}$, the Food and Drug Administration, or the American Heart Association. The funding sponsors had no role in study design; data collection, analyses, or interpretation; manuscript preparation; or the decision to publish the results.

PROVENANCE AND PEER REVIEW

Not commissioned; externally peer reviewed. 